\title{
Therapeutic Workshops as Spaces of Interaction and Psychosocial Rehabilitation: Analysis from Basic Lexicography
}

\begin{abstract}
Aline Raquel de Sousa Ibiapina1, Claudete Ferreira de Souza Monteiro², Márcia Astrês Fernandes ${ }^{3}$, Antonio Germane Alves Pinto ${ }^{4}$, Delmo de Carvalho Alencar ${ }^{5}$, Antonio Alberto Ibiapina Costa Filho ${ }^{6}$, Daniele Martins de Sousa ${ }^{7}$
\end{abstract}

\section{Abstract}

Aim: To analyze by means of the basic lexicography, the most frequent vocabulary in the reports of the health professionals about therapeutic workshops and its relation with the psychosocial rehabilitation of the PCC users.

Methods: A descriptive study with a qualitative approach developed with seven professionals from a Psychosocial Care Center in a city in the Northeast of Brazil. The data were obtained through interviews, which were processed in the IRaMuTeQ software and analyzed by the word cloud and similarity analysis.

Results: The most frequent words in the word cloud were "activities, workshop, caps" and in the similarity tree the most prominent lexicons were: more, workshop, activity, therapeutic, patient, work and no.

Conclusion: The software consented to consider carefully the material collected, qualifying the process of categorization and connectivity between words, assisting in the identification of the representation structure and enabling the visualization of the understanding of therapeutic workshops as spaces of interaction and socialization and as an important device for treatment for the individual with psychic suffering at the Center for Psychosocial Attention.
1 Nurse. Master in Nursing from the Federal University of Piauí. Member of the Group of Studies in Nursing, Violence and Mental Health of the Federal University of Piauí.

2 Nurse. PhD Professor in Nursing, PostGraduate Program in Nursing, Federal University of Piauí. Researcher at CNPq.

3 Nurse. PhD in Sciences from the University of São Paulo. Member of the Research Group on Health and Work at the University of São Paulo. Adjunct Professor, Federal University of Piauí.

4 Nurse. PhD in Nursing, Regional University of Cariri.

5 Master in Nursing from the Federal University of Piauí (UFPI). Nurse of the Family Health Strategy of the municipality of Pio IX, Piauí, Brazil.

6 Biologist. Statistical Student at the Federal University of Piauí

7 Master in Nursing, Federal University of Piauí. Professor at UNINOVAFAPI.

\section{Contact information:}

Delmo de Carvalho Alencar.

Address: Rua Josias Antão de Carvalho, 103, Centro, Pio IX. Piauí, Brasil. ZIP code: 64660-000.

झ delmo-carvalho@hotmail.com 


\section{Introduction}

The Brazilian Psychiatric Reform has led to significant changes in the care of people with mental disorders. One of the changes is the implementation of the Psychosocial Care Centers (PCC), aimed at the reception, care and social exchanges with the development of skills, autonomy and exercise of citizenship of individuals.

The PCC stand out as alternatives to the psychiatric hospital, organizing itself as spaces of creativity, building life through bridges with society. They are configured with a new methodological approach, viewing to understanding the complexity of relationships, exchanges and the health care process itself, since it is a process of dialogical-reflexive development on the part of health professionals. [1-2]

The actions carried out in the CAPS environment have the purpose of enabling the re-socialization of the individual with mental disorder and are usually carried out through therapeutic groups, with emphasis on activities guided by therapeutic workshops.

In general, the therapeutic workshops are developed individually and / or in groups with individuals who follow intensive, semi-intensive and non-intensive follow-up in CAPS. The following are among the therapeutic activities: celebrations at commemorative dates, assemblies and meetings, artistic activities (corporal, gestural and musical expression), as well as guidelines on the importance of the use of psychotherapeutic medications and community activities, focusing on the social integration of the user in the Family and community. [3]

These aim at the socialization, expression and social insertion of the individual, the manifestation of feelings and problems, the development of corporal abilities, the accomplishment of productive activities and the collective exercise of citizenship. [4] We emphasize that this process of psychosocial rehabilitation in users with mental disorders is characterized by the facilitation of the autonomy of their capacities in their daily life and by the increase of their personal abilities aiming at diminishing the deficiencies and damages caused by the mental disorder through certain actions Aimed at increasing these capacities and reducing these damages, reinserting the person into society. [5-6].

To achieve its purpose, the therapeutic workshops, as devices of the current National Mental Health Policy aim to differentiate in relation to their predecessor practices and also point to the need for a diversified performance of the multidisciplinary team. Thus, instead of labeling the subject who suffers from a pathology, it is proposed that through listening, the individual can share their experiences and feelings and realize that the health professional can help him in their psychosocial rehabilitation. [7]

Therefore, promoting psychosocial rehabilitation as a fundamental paradigm of this new modality of mental health care is to elect activities and actions that motivate the aspirations, desires and choices of users and their families, respecting their subjectivities, as well as valuing co-participation and coresponsibility. [8]

In addition, health professionals should be prepared, besides hosting, to develop a work with collective characteristics and with an interdisciplinary team in the search for psychosocial rehabilitation. However, it is a complex activity, since it requires health professionals to reconstruct their professional work in mental health, starting from, for example, changes in their postures in front of the other.

In this sense, the nurse and the interdisciplinary team should welcome the mentally ill and convey to him their sincere desire to help him, always valuing them within their particularities, with the purpose of promoting and providing a better quality of life. In this context of contribution to mental health, the nurse emerges as a differentiated professional, since its actions are directed towards a holistic approach, considering the individuality of the human being, the context of health and illness in which the user is inserted and interpersonal relationship. 
Therefore, our interest in this topic emerged from the need to show this universe of existing opportunities for the development of a practice of the multiprofessional team in mental health, guided by the use of policies guided by the new paradigm proposed by the psychiatric reform and show the importance of implementation of the therapeutic workshops in the CAPS, as an odd factor for the rehabilitation and reinsertion of the patient in society.

Based on this interest, the construction of this study was valid, with the objective of: To analyze by means of the basic lexicography, the most frequent vocabulary in the reports of the health professionals about therapeutic workshops and its relation with the psychosocial rehabilitation of the PCC users.

\section{Methods}

This is a research with a qualitative and exploratory approach, carried out at the Center for Psychosocial Care of the city of Fronteiras, Piauí State, Northeastern region of Brazil.

Participated in the study 7 health professionals who were part of the PCC team of the municipality studied. Professionals who were not included in the activities of therapeutic workshops with PCC users were excluded.

Data collection took place in the period from November to December 2014, through a semistructured on-site interview and work shift of the health professionals, by prior appointment in a reserved room, with an average duration of 40 minutes, composed of two groups of questions, the first group being related to gender, age, origin, university formation, training time, time spent in the PCC and working in another psychiatric institution, and the second group sought to know the professionals' perceptions on the therapeutic workshops within the PCC, allowing the interviewee to freely discuss the subject.

Participants' discourses were digitally recorded and transcribed in full by the researcher and the participants were coded (Dep.1 to Dep.7) to guarantee anonymity.

For the processing of the data, the software IRaMuTeQ (Interface de R pour lês Analyses Multidimensionnelles de Textes et de Questionnaires), developed by Pierre Ratinaud, whose purpose is to discover the essential information contained in a text, through textual statistical analysis. Although there is said of a quantitative analysis of textual data, this does not fail to consider the quality of the studied phenomenon, and also provides criteria from the material itself, for the consideration of it as an indicator of a scientific interest phenomenon. The IRaMuTeQ makes possible different types of analysis, from the simplest to the multivariate, among them we can present: classic textual statistics; Research of group specificities; Descending hierarchical rank; Cloud of words and analysis of similitude. [9] Studies using the software allied with an in-depth analysis of the data, it has been very successful. [10-13]

In this study, the word cloud and similarity analysis were used for data processing. Thus, the word cloud is represented as grouped words and organized graphically according to their frequency, which makes it possible to identify them from a file processed by the Software, called corpus, which brings together the texts originated by the interviews. Thus, each interview is characterized as a text, and separated by the decodings being constituted and denominated as the corpus of analysis of this research. [9]

The analysis of similarity is based on the theory of graphs that makes it possible to identify the competitions between the words and their result indicates indications of the connection between the words, aiding in the identification of the structure of the representation of the phenomenon under study. From the most frequent words provided in the text segments, the lexical analysis was performed. This analysis allows quantitative and qualitative research to be carried out, using statistical calculations on 
qualitative data. In this sense, the vocabulary is identified and quantified under statistical calculations for later interpretation being one of the differences of the content analysis, in which the researcher interprets and then systematizes. [9]

The ethical aspects were respected, following the norms for research with human beings - Resolution of the National Health Council, No. 466, of December 12, 2012. Obtained approval from the Research Ethics Committee of the Federal University of Piauí (UFPI) with opinion of CAAE $n$. 34827514.2.0000.5214.

\section{Results and Discussion}

The results will be presented in two aspects: professional characterization and lexical analysis - word cloud method and similarity analysis.

Regarding the characterization of the participants, of the 7 professionals interviewed, the majority (90\%) were female, with ages ranging from 24 to 66 years. Regarding the professional category, one was a nurse, a psychologist, a social worker, a doctor, a nurse technician, an artisan and a pedagogue. The majority of the participants came from Fronteiras, PI.

The time of professional training ranged from 2 to 41 years, 2 of them had a technical level, 5 had a higher level, 4 had a degree in Latu Senso, 2 in Mental Health, 1 in Family Health and 1 in Social Project Management, however only 1 who had no specialization. The performance in the municipality studied ranged from 5 months to 1 year, and among them only one worked in another psychiatric institution.

It was observed that the research participants are concerned with acquiring new knowledge as a way of complementing those acquired at the undergraduate level, as well as offering better quality care to the client, at the same time becoming worrisome when revealing the lack of active professional specialists In this area of mental health, since only two have specialization in this area, being of fundamental importance the professional update, so that the assistance is not based on old concepts.

The word cloud method is a form of textual analysis that groups and organizes the terms most frequently of the words presented by the participants, clearly and visually, the word "activity and workshop" was the most frequent in the corpus 970 times, Followed by the word therapeutic - 380 times (Figure 1).

Figure 1: Word cloud, organized based on IRAMUTEQ software. Teresina. 2015.

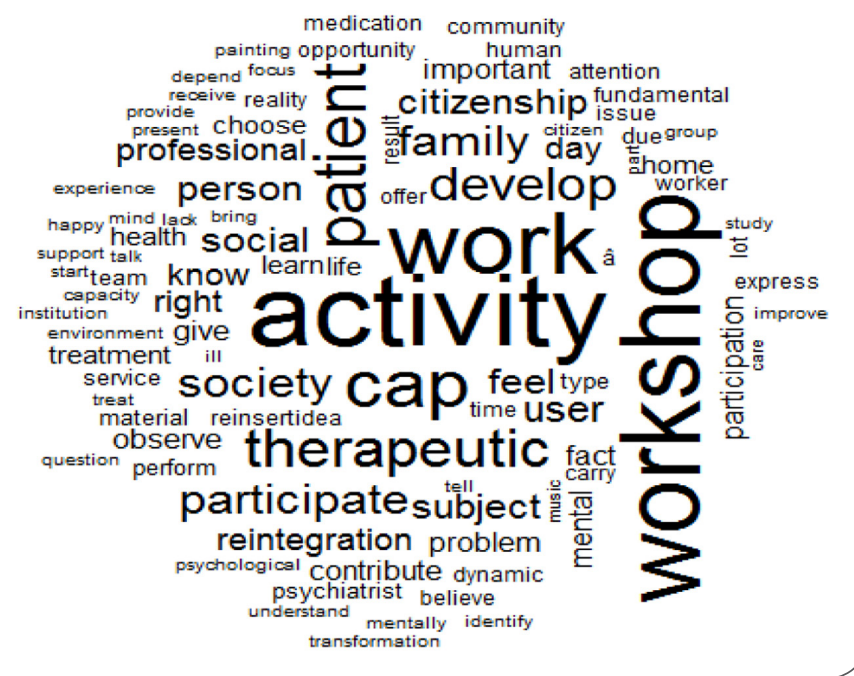

It is observed in Figure 1 that the words are arranged so that the most frequent words in the participants' speeches appear larger than the others, thus proving their prominence in the corpus of research analysis. Therefore, after the processing steps, the meanings of the words most evoked in the professionals' discourses were analyzed and interpreted.

The terms presented larger and to the center of the graph are more frequent, whereas the margins in smaller sizes are less frequent. The term "activity" stands out because it is the most cited and portrays the professionals' perception of the dynamics of therapeutic workshops, focused on the activity carried out by its protagonists, the users, allied to the work of these professionals in PCC. 
The development of the workshops stands out for having a therapeutic proposal based on the development of actions focused on work as an effective way of psychosocial rescue and favorable to the reinsertion of the subject to its social context, strengthening a healthy relationship between patient, family and professionals. This security developed through the rescue of the citizenship of the users through the learning and execution of various tasks provides their self-affirmation as an important social being who has rights and duties and actively participates in a society.

Treatment gains a sense that beyond the traditional, drug only, and is enhanced with painting workshops, drawings, embroidery, cutting and pasting, among others. This relationship of teaching is seen by professionals as quite favorable to the reintegration of this active subject that is rediscovered as a citizen. The professionals develop an affective bond of affection and concern, verified in the perspecti- ve they express in contributing to the progress of the patients and provide alternatives that return the subject's opportunity to feel important, want and find it possible to improve and get rid of a psychic problem, being reinserted in their daily activities within their social life.

Providing the user with psychosocial attention in the perspective of integrality means not only visualizing the mental disorder but seeing it as the subject of his own history, which has dreams, fears, expectations and needs that surpass health, so that he can once again lead his life. [14]

The similarity analysis method makes it possible to identify the occurrences between the words and their result, bringing indications of the connection between the words and assisting in the identification of the representation structure [9] (Figure 2).

The representation "more" is associated with opportunity, treatment, family, team, social and other lexics expressed in the way of perceiving therapeutic

Figure 2: Similitude Analysis, organized in IRAMUTEQ software. Teresina. 2015.

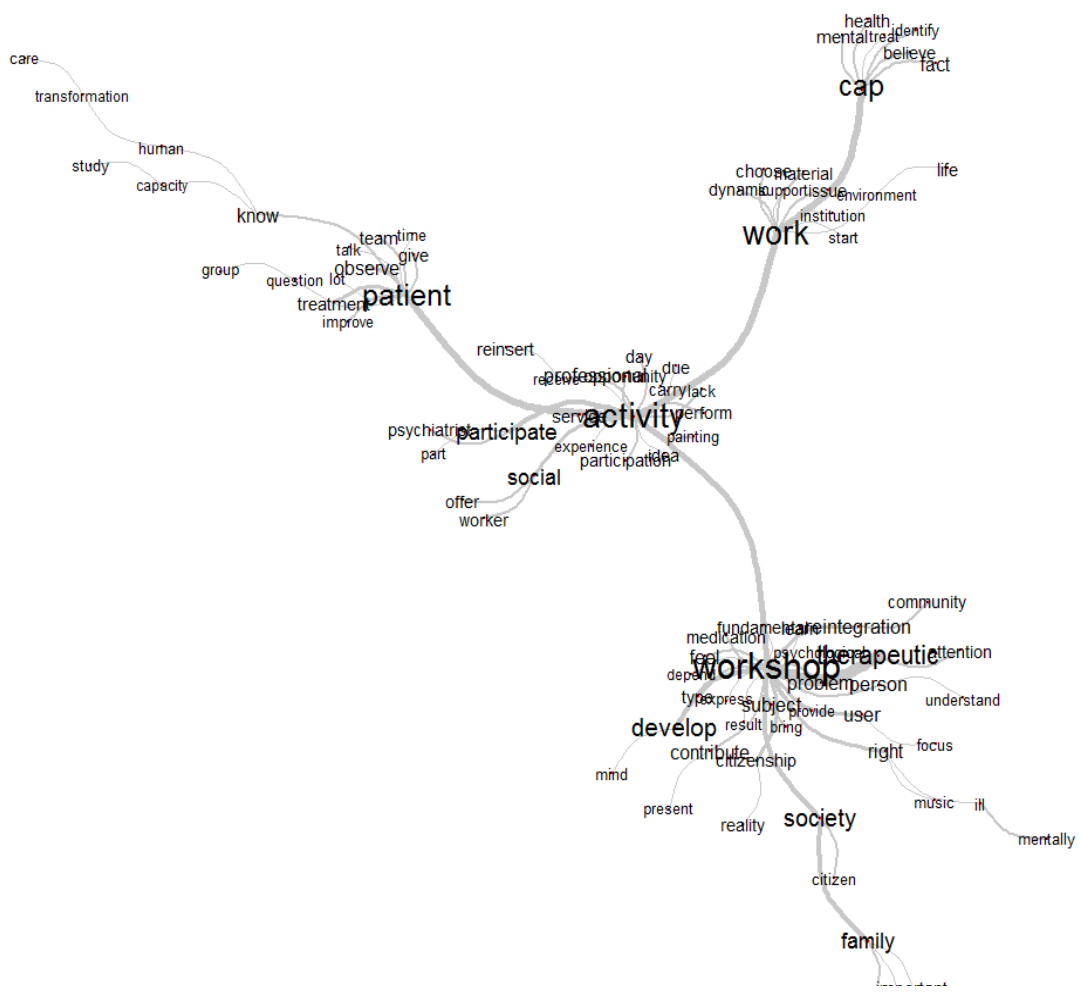


workshops as an instrument of social rehabilitation. In the workshops, the patient improves their relationship in the cycle of social and family coexistence and this is seen as a factor that enhances the effectiveness of the treatment, becoming fundamental for the development of their abilities, self-valorization and well-being, placing the patient at a level of satisfaction and clinical improvement that correspond to the professionals' expectations.

The development of therapeutic workshops allows users of services a place that can speak, express themselves and be welcomed. In addition, it facilitates the path of rehabilitation, in order to play the role of a constructive device of the psychosocial paradigm. [15]

Psychosocial rehabilitation aims to consider the individual in all sociocultural aspects, and is characterized by a set of activities developed in the PCC with the purpose of reintegrating individuals into society. In this way, it is important that the multiprofessional team reinforce the presence of family members in the treatment of the user, informing them that they are partners and responsible for the treatment of the user. It is through this participation that it is possible to achieve adherence to treatment based on the mutual bond and responsibility required, approaching and approaching the ideal family insertion in the mental health service [16].

The word "workshop" (Figure 2) has a strong similarity with "therapeutics", and with other connections such as "reality, reinsertion, society and user". In this similarity it is perceived that a valorization of this activity is attributed capable of strengthening the action of the subject and its reintegration in the society through activities that give back the right to the citizenship, once forgotten and abandoned as a consequence of a mental problem.

In the PCC, the activities of therapeutic workshops constitute a therapeutic resource, aiming to promote the development of cognitive, communicational, relational and contractual skills, equipping the subjects for the exercise of citizenship, self- care and social reintegration. These activities are developed in group forms with a view to greater social and family integration, to the manifestation of feelings and problems, to the development of corporal abilities and to the collective exercise of citizenship. [17]

A study carried out in CAPS type I of a city in the northeast of Brazil in 2009, whose objective was to investigate the mental health actions aimed at the psychosocial rehabilitation of the sufferer of psychic suffering in the CAPS, it was identified that the users participate effectively in group therapies . He pointed out a significant improvement in his life condition, especially in relation to sociability, from the increase of art in the caring process, which humanizes and contributes to the improvement of the general health picture. [18]

The lexicon "as" refers to affinity with other words expressed by "also, form, citizen, human, contribute, reinsert" and others, demonstrating that professionals perceive the user as a citizen, human, able to contribute and achieve reinsertion both social and family.

The workshop space within the PCC is designed with a dimension that encompasses issues involved in the work process of the multidisciplinary team, the user is seen by multiple looks, understood in a holistic way, not only by his formal speech before a clinical professional, but also by its diversity of psychic manifestations, which it becomes visible, interacts, exchanges knowledge and affections, expanding its circle of friendships and interactions. [19]

A study carried out in 2011 in a city in southern Brazil aiming to analyze the daily practices of professionals showed that the spaces found in the CAPS are promoting interaction between the team and users of the service, resulting from the initiative of both professionals and users, In collectively building the therapeutic project and team meetings. [14] This is a driving force for the realization of the integrality of care, so desired by the health system in the country. [18] 
Another word that emerged was "activity" linked to "painting, knowing, executing, achieving" as activities that are apprehended by the patients and end up transforming what they have learned into an income-generating craft for the family. This opportunity brings the subject closer to the community and family in a way that feels useful and responsible, returning to everyday life as an active being, feeling very important.

Therapeutic workshops promote psychosocial rehabilitation through thinking and acting, as well as the social insertion of isolated and idle individuals, and their recovery as citizens, through practices that basically pass through the insertion of the patient in the work and/or artistic activities, crafts, or to give them access to the means of communication among others. [20] For this, the manual learning of these handmade techniques is conceived and punctuated by professionals as a great rehabilitation resource that has the potential to contribute to the independence of the user, transforming it as a generator of income.

It also observed in Figure 1 another representation, the "therapeutic" word, which has similarity to group depend feel and which is connected to the branch of the "workshop". The professionals express the workshop activity as depending on a group with ability to feel and develop with the users ties of trust and transformation.

The user inserted in the therapeutic workshop finds opportunities to approach other people, or even rebuild their social environment and consequently strengthen family ties, making the person feel more useful in being in society, since they have a dynamic that breaks with the isolation, allowing its construction as being, through its productions.

Group therapies have been shown to be an increasingly important activity in the process of rehabilitation and social inclusion. Several factors contribute to the growing emphasis on group work among them, the proposal of interdisciplinarity in health;
The rationalization of the time of execution of the activities, that could not be developed individually; The rescue of the socialization of patients and the fight against individualism. [21]

In another axis comes the word "patient", there is connection with the words "develop, capacity, improvement, mainly". These terms are present in the professionals' discourses when they refer to the evaluation and follow-up done by them to the patients and their perception about the development, capacity and improvement according to the participation in the activities in the PCC.

It is considered that, in these workshops, the user is the focus of attention developed and has the option to choose what he wants to accomplish, or nothing to accomplish, because nothing is imposed. In addition, the user is encouraged to interact with the group and with the professionals, which clearly demonstrate that it has importance in the treatment space. In this way, we can see in these services the process of consolidation of new practices in mental health, in which the subject in psychic suffering that previously had an inactive and exclusionary position now inserts in a level of participation, of exchanges, of reconstruction of their daily life. [22]

They begins to exercise their "contractuality", expresses decision-making power over themselves, their treatment, the activities which wishes to accomplish, thus exercising citizenship. In this context, is not merely an author of works, but author of their own life. [5]

However, we know that every social process of transformation is not linear, but rather made up of advances and setbacks. If in some CAPS, progress has been made in the process of consolidation of the psychosocial care mode, with the conscious use of technologies that favor the execution of the proposed project (to promote the exercise of citizenship and the family, social and political reintegration of the subjects), in theirs, the practices developed are still in the old molds of psychiatric care. 
Another demonstrated representation that has connection with the words "more" and "people" is the expression "to work". There it is indicating a possible work of attention and transformation. The transformation of the forms of mental health care is feasible and favors the implementation of the proposal of the psychiatric reform, in which the user receives a care that respects their citizenship and autonomy. [23]

Also, as a negative expression, the word "no" appears, whose similarity is on the axis of "activity", demonstrating a way of expressing the denial of being "alone", not staying in "home", And identify "PCC" as a health facility.

The PCC as substitutive services to the hospitalcentered model has a great demand for treatment, since in this service various resources are used, such as therapeutic support activities, seeking psychosocial rehabilitation of the user, reinserting the individual in society with the family and community. The CAPS have been offering a variety of activities to their users and their families. These activities have the objective of providing care, treatment and follow-up of users aiming at their social inclusion and rescue of citizenship, making the individual feel well in this treatment environment, [1]

Figure 2 shows that the therapeutic workshops are perceived by professionals as an important device for treatment in the PCC, ranging from the opportunity, the treatment, the insertion of the family, a look at the team, the humanization and the work that is developed in order to improve the picture of mental suffering and the process of social reintegration.

A study carried out in 2006 in the south of Brazil aimed to know the characteristics of mental health care offered by the CAPS from the perspective of its professionals. This study identified the concern of the professionals before the proposal of psychosocial rehabilitation, pointing out the commitment that they assume, daily, with the transformation of the care model in mental health, for believing in inclusive and rehabilitative therapeutic practices, centering its care in the existence of the user with its history of life. [24]

\section{Conclusion}

This research allowed to appreciate, through the basic lexicography, the vocabulary of the words most frequent in the speeches of the participants of this research, experienced by the health professionals of the Psychosocial Care Center team of a municipality in the Northeast of Brazil. In this way, the IRaMuTeQ software presented itself as an innovative tool in the analysis of this study, in which it allowed to look carefully at the material collected, quantifying and qualifying the categorization process and, thus, enhancing the results of a qualitative research.

The word cloud and similarity analysis identified the most frequent words and connections in the participants' discourses, which corroborates the effectiveness of the Mental Health Policy that therapeutic workshops are spaces for interaction and socialization and must be understood as an important device For the treatment of the individual with psychological distress, in the promotion and reconstruction of the user's identity, their entry into the labor market through income generating workshops and their better insertion in the family and community.

The present study made it possible to understand that health professionals incorporate the guidelines of the Mental Health Care Policy regarding the therapeutic workshops and recognize the importance of this work and the benefits provided for the social rehabilitation of the users served in the CAPS.

\section{References}

1. Kantorski LP, Coimbra VCC, Demarco DDA, Eslabão AD, Nunes CK, Guedes ADC. The importance of therapeutic support activities for the attention in a Psychosocial Care Center. J Nurs Health.2011; 1(1):4-13. 
2. Ministério da Saúde. Secretaria de Atenção à Saúde. Saúde Mental no SUS: os centros de atenção psicossocial. 1th ed. Brasília: Ministério da Saúde, 2004. Disponível em: http://www. ccs.saude.gov.br/saude mental/pdf/sm sus.pdf. Acesso 07 jul 2015.

3. Rocha RM. O enfermeiro na equipe interdisciplinar do centro de atenção psicossocial e as possibilidades de cuidar. Texto Contexto Enferm. 2005; 14(3):350-357.

4. Amarante P. Saúde mental e atenção psicossocial. 2nd ed. Rio de Janeiro: Editora Fiocruz, 2007.

5. Saraceno D, Autoorganización UM. A proposta de reabilitação psicossocial de Saraceno: um modelo de auto-organização? Rev Latino-am Enferm. 2006; 14 (3): 448-56.

6. Jorge MSB, Randemark NFR, Queiroz MVO, Ruiz EM. Reabilitação Psicossocial: visão da equipe de Saúde Mental. Rev Bras de Enferm. 2006; 59 (6): 734- 9.

7. Pinho LB, Kantorski LP, Wetzel C, Schwartz E, Lange C, Zillmer JCV. Atividades terapêuticas: compreensão de familiares e profissionais. Esc Anna Nery. 2013; 17(3):534-41.

8. Azevedo DM, Miranda FAN. Oficinas terapêuticas como instrumento de reabilitação psicossocial: percepção de familiares. Esc Anna Nery. 2011; 15(2):339-45.

9. Camargo BV. Alceste: Um programa informático de análise quantitativa de dados textuais. In: Moreira ASP. Perspectivas teórico-metodológicas em representações sociais. João PessoaPB: Editora Universitária, 2005.

10. Sousa AFL, Queiroz AAFLN, Oliveira LB, Valle ARMC, Moura MEB. Social representations of community-acquired infection by primary care professionals. Acta paul enferm. 2015; 28(5):454-9.

11. Moura LKB, Marcaccini AM, Matos FTC, Sousa AFL, Nascimento GC, Moura MEB. Integrative review on oral cancer. Rev Pesq Cuidad Fund (Online). 2015; 6(5):164-75.

12. Mendes FRP, Zangão MOB, Gemito MLGP, Serra ICC. Representações sociais dos estudantes de enfermagem sobre assistência hospitalar e atenção primária. Rev Bras Enferm. 2016; 69(2):343-50.

13. Sousa AFL, Queiroz AAFLN, Oliveira LB, Moura MEB, Batista OMA, Andrade D. Social representations of biosecurity in nursing: occupational health and preventive care. Rev Bras Enferm. 2016; 69(5):864-71

14. Pereira DB, Coimbra VCC, Kantorshi LP, Oliveira MM, Soares MC, Schrader G. A integralidade no cotidiano das práticas em um centro de atenção psicossocial. Cogitare Enferm. 2011; 16(3): 430-6.

15 Lappann-Botti NC, Labate RC. Oficinas em saúde mental: a representação dos usuários dos serviços de saúde mental. Texto-Contexto Enferm. 2004; 13(4): 519-26.

16. Dixon L, McFarlane WR, Lefley $H$, Lucksted A, Cohen M, Falloon I, Sondheimer D. Evidence-based practices for services to families of people with psychiatric disabilities. Psychiatric services. 2014; 52(7):903-10
17. Ribeiro LA, Marin LL, Silva MTR. Atividades grupais em saúde mental. Revista Baiana de Enfermagem. 2014; 28(3):283-93.

18. Neves JA, Silva PMC, Azevedo EB, Muss JO, Filha MO. Ações do centro de atenção psicossocial para a reabilitação do portador de sofrimento psíquico. Cogitare Enferm. 2012; 17(2): 255-61.

19. Santos EO, Willrich JQ, Meneses BHSR, Franchini B, Antunes B, França SM. Serviços substitutivos na perspectiva da reabilitação psicossocial: um relato de experiência. Cienc Cuid Saude 2013; 11(3):588-92.

20. Middleton J, Perry KN, Craig A. A Clinical Perspective on the Need for Psychosocial Care Guidelines in Spinal Cord Injury Rehabilitation. Int J Phys Med Rehabil. 2014; 2(226):1-6.

21. Cavalcante TF, Guedes NG, Moreira RP, Guedes TG, Araújo MAM. Nursing care at new mental health services - experience report. Online braz J Nurs. 2006; 5(1):23-9.

22. Marini M, Brandalise GB, Schnornberger TM, Heldt E. Abstinence predictors among substance dependents treated in a Brazilian psychosocial care center. International Journal of Psychosocial Rehabilitation. 2012; 16(1):125-35.

23. Brêda MZ, Rosa WAG, Pereira MAO, Scatena MCM. Duas estratégias e desafios comuns: a reabilitação psicossocial e a saúde da família. Rev Latino-Am Enferm. 2005; 13(3):450-2.

24. Mielke FB, Kantorsk LP, Olschowsky LP, Jardim VMR. Características do cuidado em saúde mental em um CAPS na perspectiva dos profissionais. Trab Edu Saúde. 2011; 9(2):26576.

\section{Publish in International Archives of Medicine}

International Archives of Medicine is an open access journal publishing articles encompassing all aspects of medical science and clinical practice. IAM is considered a megajournal with independent sections on all areas of medicine. IAM is a really international journal with authors and board members from all around the world. The journal is widely indexed and classified Q2 in category Medicine. 